\title{
Penggunaan Medial Arch Support pada Kemampuan Motorik Kasar Siswa kepada Siswa, Guru, dan Orang Tua
}

\author{
M. Syafi'i ${ }^{*}$, Atika Febri Anggriani ${ }^{2}$ \\ 1,2 Jurusan Orthotik Prostetik, Poltekkes Surakarta \\ *Email: amfi86@gmail.com
}

\begin{abstract}
Background: Gross motor skills are the ability to move limbs that involve nerves, bones, and muscles, to perform certain activities (balance standing, walking, running, and jumping). To be able to do this, a person needs a normal body structure including the foot. A person will experience obstacles when the foot has a structural abnormality, one of which is the flat foot. Flat foot is a condition where the foot does not have a normal arch / flat foot. One of the treatments performed on flat foot sufferers is by giving foot orthosis in the form of Medial Arch Support. Medial arch support is a tool used to improve stability and improve walking function. Methods: According to a preliminary study conducted at SDN 1 Tohudan there were 47 students from grades 3 to 6 who experienced flat foot. This is known from the results of early detection of flat foot carried out at SDN 1 Tohudan. The approach method to be chosen is (1) Assessment for early detection of flat foot conditions, (2) health promotion by training for students, parents, and teachers to increase knowledge about flat foot problems that have an impact on children's gross motor skills so it needs to be done. intervention with the use of medial arch support, with the aim of improving students' gross motor skills. Results: After community service activities run, the understanding of students, parents, and teachers who are the targets / targets in this activity gets better, they become better at understanding the basics of flat foot, which results in a decrease in gross motor skills and increasingly realizes the importance of handling it by using medial arch support. Conclusions: The implementation of community service activities can increase the knowledge of students, teachers and parents about the effect of using medial arch support on the gross motor skills of students with flat foot.
\end{abstract}

Keywords: flat foot, gross motor skills, medial arch support

\section{PENDAHULUAN}

Kemampuan motorik pada buku karya Endang Rini Sukamti (2007) yang menuliskan pendapat Hurlock merupakan perkembangan pengendalian mobilitas jasmaniah melalui aktivitas sentra saraf, urat saraf, dan otot terkoordinasi . Yhana (2015) pada peneltiannya menuliskan pendapat Bambang Sujiono (2007) bahwa gerakan motorik kasar merupakan kemampuan yang membutuhkan koordinasi sebagian besar bagian tubuh anak.

Kemampuan motorik sangat krusial dalam periodesasi kehidupan anak lantaran kemampuan motorik kasar dibutuhkan anak buat melakukan banyak sekali kegiatan misalnya duduk, menendang, berjalan, melompat, berlari, naik turun tangga, dan sebagainya (Endang, 2007). Gerakan motorik kasar melibatkan kegiatan otot-otot besar misalnya otot tangan, otot kaki dan semua tubuh anak. Gerakan motorik kasar sangat berkaitan erat menggunakan sistem muskuloskeletal lantaran pada perwujudan gerakan motorik kasar memerlukan koordinasi yang baik menurut sistem saraf sentra, syaraf, dan otot-otot besar .

Tulang-tulang lengkung kaki (arcus pedis) disatukan ligamen dan didukung otot. Lengkung-lengkung kaki bisa bertahan lantaran letak tulang yang berdempetan secara serasi, ligamen pada kaki bertenaga, dan kerja otot, khususnya otot yang 
dikaitkan pada depan dan belakang tibia (Pearce, Evelyn C.,2006). Adanya arcus pedis membantu memperkuat kaki dalam ketika berjalan \& berlari (Wibowo, Daniel., 2015).

Fungsi arkus longitudinal artinya menaruh gaya pegas ketika berjalan (Idris, 2010). Lengkungan dalam kaki menambahkan elastisitas dan fleksibilitas, membantu kaki pada menyerap kejutan (absorb shock) mengatur ekuilibrium, berdiri, berjalan, berlari dan melompat. (Erol K., et al, 2015).

Pes planus atau flatfoot merupakan hilangnya lengkungan longitudinal medial kaki. Hal ini bisa sebagai fleksibel atau kaku seumur hidup, atau seiring menggunakan peradangan ataupun perkara muskuloskeletal (Erol K., et al, 2015).

Kondisi ini mampu tentang satu atau ke 2 kaki, seorang menggunakan arkus rendah atau tidak mempunyai arkus umumnya menunjuk buat syarat yang diklaim kaki datar (Utomo, Prasetyo., 2018). Para pakar dibidang foot \& ankle menyatakan bahwa deformitas flatfoot adalah patologi yang $\mathrm{g}$ acapkali ditemukan dalam gerombolan pediatri (Harris, 2004). Pernyataan World Health Organization (WHO) yg ditulis sang Prasetyo (2018) menyatakan bahwa masih ada ratusan juta orang terganggu kehidupannya dampak gangguan musculoskeletal yang poly dijumpai merupakan flatfoot.

Penelitian yang dilakukan Ockta (2016) tentang Hubungan Arcus Pedis Terhadap Kelincahan Motorik Kasar pada Anak menampakan bahwa adanya interaksi yang bertenaga antara arkus pedis kelincahan anak menggunakan nilai koefisien hubungan 0,771>0,5999. Sedangkan dari data fakta pada Sekolah Dasar N Tohudan 1 Surakarta dalam 80 anak didik dihasilkan output 31 anak didik mengalami deformitas flatfoot bilateral. apabila dipresentasekan maka masih ada 40.25\% anak didik pada Sekolah Dasar N Tohudan 1 mengalami flatfoot bilateral.

Pada bidang ortotik prostetik penanganan flat foot dilakukan menggunakan penggunaan medial arch support. Medial arch support didesain buat mengontrol penyelarasan, fungsi kaki \& anggota tubuh bagian bawah, dan dipakai buat membatasi gerakan misalnya pronasi berlebih. Orthosis ini tidak hanya bekerja menggunakan prinsip buat menopang arcus pedis, namun jua memperbaiki balik struktur kaki buat mencegah kelainan dalam tulang, otot, tendon, dan kelelahan ligamen (Santoso, 2011). Dari penelitian sebelumnya disampaikan juga bahwa penggunaan medial arch support bisa berpengaruh terhadap kemampuan motorik dalam anak penderita flatfoot.

Dari latar belakang tadi maka perlu adanya aktivitas penyuluhan menggunakan pengajar, anak didik \& orang tua anak didik buat menaikkan pemahaman mengenai efek penggunaan medial arch support terhadap kemampuan motorik kasar anak didik penderita flatfoot.

\section{TINJAUAN PUSTAKA}

\subsection{Arkus Kaki}

Tulang-tulang pada kaki bersatu membentuk arkus atau lengkung kaki. Adanya arkus memungkinkan kaki buat menyangga berat menurut tubuh, menaruh distribusi berat badan yang merata dalam keseluruhan jaringan yang lunak juga yang keras 
pada kaki dan berfungsi menjadi pengungkit waktu proses berjalan. Arkus-arkus kaki tidak rigid, tetapi bersifat fleksibel. Arkus akan mendapat berat ketika posisi menumpu dan balik ke bentuk semula ketika berat badan tidak ditumpu. Kemampuan tadi sangat membantu kaki buat meredam kejut. Biasanya, arkus dalam kaki secara holistik berkembang pada saat anak-anak dalam usia 12 atau 13 tahun (Tortora, Gerard, J. 2017).

Tulang-tulang lengkung kaki disatukan ligamen dan didukung otot. Lengkunglengkung kaki bisa bertahan lantaran letak tulang-tulang yang berdempetan secara serasi, ligamen pada kaki bertenaga dan kerja otot, khususnya otot yang dikaitkan pada depan dan belakang tibia (Pearce, Evelyn C., 2013). Adanya lengkung kaki membantu memperkuat kaki dalam ketika berjalan \& berlari (Wibowo, Daniel., 2015).

\subsection{Flatfoot}

Flatfoot adalah syarat dimana kaki tidak mempunyai lengkungan telapak kaki atau arkus yang normal. Kondisi ini mampu tentang satu atau ke $2 \mathrm{kaki}$, seorang menggunakan arkus rendah atau tidak mempunyai arkus umumnya menunjuk buat syarat yang diklaim kaki datar. Kaki datar atau flatfoot mempunyai nama lain baik pada kata medis juga kata asing yaitu pes planus, pes planovalgus, fallen arches, pronation of feet, excessive pronation, \& talipes calcaneal valgus (Utomo, Prasetyo., 2018).

Para pakar dibidang foot dan ankle menyatakan bahwa deformitas flatfoot adalah patologi yang ditemukan dalam gerombolan pediatri. Medial arkus yang datar merupakan syarat yang generik dijumpai dalam perkara flatfoot (Harris, 2004).

Flatfoot merupakan kelainan kompleks yang acapkali terjadi dan sering ditemui pada lahan, menggunakan beragam tanda-tanda menggunakan derajat deformitas and disability yang beragam, terdapat beberapa tipe kaki datar yang semuanya ditinjau menurut keadaan arkus yang hilang baik sebagian juga holistik. Ciri karakteristik klinis yangg primer menurut flatfoot merupakan adanya pronasi yangg hiperbola dalam kaki (Utomo, Prasetyo., 2018).

\subsection{Medial Arch Support}

Medial Arch Support adalah jenis orthosis yang dipasang dalam bagian medial archus longitudinalis pedis. Medial Arch Support berfungsi menjadi shock breaker tumpuan berat badan dalam kaki, buat support bagian medial archus longitudinalis pedis dan menaruh stabilitas dalam kaki (Nadiaty, 2015). Pemberian medial arch support ini diperlukan archus longitudinalis pedis sebagai lebih stabil, penumpuan berat badan sebagai lebih normal dan ekuilibrium tubuh semakin tinggi dan fungsi berjalan sebagai lebih baik (Aziz, 2017).

Pada bagian medial dibuat sebuah lengkung yang dipakai buat support dalam archus pedis. Pada bagian heel pad akan meredam atau mengurangi daya tekan dalam bagian heel. Tekanan plantar foot akan didistribusi dalam bagian arch support, metatarsal shaft, heel hingga dalam bagian forefoot. Secara biomekanik, dalam bagian medial wedge akan menunda beban kaki terutama bagian midfoot 
(tengah kaki) menjadi shock absorber sebagai akibatnya mencegah terjadinya pronation foot yang menciptakan ekuilibrium terganggu. Foot orthosis menggunakan medial arch support, metatarsal pad dan heel cups bisa menaikkan ekuilibrium statis, bergerak maju dan pola berjalan (Ma et al, 2016).

\subsection{Kemampuan Motorik}

Manusia pada dasarnya telah dibekali kemampuan mobilitas, mobilitas adalah bagian yang tidak bisa dipisahkan menurut kehidupan manusia. Kemampuan mobilitas yang terdapat dalam manusia telah terdapat semenjak insan masih didalam kandungan dan berkembang terus sepanjang hayatnya. Untuk menerima pola mobilitas yang kompleks dan harmonis, manusia wajib belajar dan berlatih sampai menerima gerakan yg luwes dan lezat dicermati mata. Manusia dikatakan terampil apabila bisa melakukan gerakan yang baik, sinkron apa yang diinginkannya dan memperoleh output yang maksimal (Prabowo, 2017).

Kemampuan motorik dari menurut bahasa Inggis yaitu motor ability, mobilitas (motor) merupakan suatu kegiatan yang sangat krusial bagi manusia, lantaran menggunakan mobilitas (motor) manusia bisa meraih sesuatu yang sebagai harapannya. Menurut Sukintaka (2001) bahwa kemampuan motorik adalah kualitas output mobilitas individu pada melakukan mobilitas, baik yang bukan mobilitas olahraga juga mobilitas pada olahraga atau kematangan penampilan keterampilan motorik. Semakin tinggi kemampuan motorik seorang akan dimungkinkan daya kerjanya akan sebagai lebih tinggi dan begitu sebaliknya. Oleh karenanya kemampuan motorik bisa dicermati menjadi dasar keberhasilan didalam melakukan tugas keterampilan mobilitas (Prabowo, 2017).

\subsection{Hubungan Medial Arh Support dengan Kemampuan Motorik Kasar pada Kondisi Kaki Datar atau Flatfoot}

Tulang-tulang lengkung kaki disatukan ligamen dan didukung otot. Lengkunglengkung kaki bisa bertahan lantaran letak tulang-tulang yang berdempetan secara serasi, ligamen pada kaki bertenaga dan kerja otot, khususnya otot yang dikaitkan pada depan dan belakang tibia (Pearce, Evelyn C., 2013). Adanya lengkung kaki membantu memperkuat kaki dalam ketika berjalan dan berlari (Wibowo, Daniel,2015).

Fungsi arkus longitudinal artinya menaruh gaya pegas ketika berjalan (Idris, 2010). Arkus longitudinal terbagi sebagai dua bagian, arkus longitudinal medial dan arkus longitudinal lateral. Arkus longitudinal medial terbentuk menurut calcaneus naik ke bagian talus dan turun melewati naviculare, 3 tulang cuneifome dan head metatarsal angka I-III (Tortora, Gerard, J. 2017).

Medial Arch Support adalah jenis orthosis yang dipasang dalam bagian medial archus longitudinalis pedis. Medial Arch Support berfungsi menjadi shock breaker tumpuan berat badan dalam kaki, buat support bagian medial archus longitudinalis pedis dan menaruh stabilitas dalam kaki (Nadiaty, 2015). Pemberian medial arch support ini diperlukan archus longitudinalis pedis sebagai lebih stabil, penumpuan berat badan sebagai lebih normal dan ekuilibrium tubuh semakin tinggi dan fungsi 
berjalan sebagai lebih baik (Aziz, 2017).

\section{METODE}

Kegiatan pengabdian masyarakat ini dilakukan melalui beberapa tahapan kegiatan yaitu :

a. Survei Awal

Survey dilakukan di sekolah SDN 1 Tohudan, Colomadu. Metode yang digunakan adalah observasi terhadap salah satu pengajar pada Sekolah Dasar Negeri 1 Tohudan, Colomadu. Dengan tujuan buat menerima fakta terkait jadwal sosialisasi menggunakan anak didik dan orang tua wali anak didik.

b. Pelaksanaan Kegiatan

Pelaksanaan aktivitas darma warga ini diwujudkan pada aktivitas pengenalan terkait pentingnya penggunaan penggunaan medial arch support terhadap kemampuan motorik kasar anak didik penderita flat foot. Kegiatan ini dilakukan menggunakan menaruh penyuluhan kesehatan melalui ceramah, diskusi mengenai penggunaan medial arch support terhadap kemampuan motorik kasar anak didik penderita flat foot. Penyuluhan pada berikan sang dosen Poltekkes Surakarta menggunakan jumlah peserta yang hadir sebesar 50 orang.

c. Evaluasi Kegiatan

Evaluasi Evaluasi dilakukan selama proses aktivitas penyuluhan mengenai penggunaan medial arch support terhadap kemampuan motorik kasar anak didik penderita flat foot.

\section{HASIL}

Sebagaimana perseteruan yang terdapat, maka dibutuhkan solusi buat menyelesaikannya yaitu menggunakan melakukan pengenalan mengenai pentingnya penggunaan penggunaan medial arch support terhadap kemampuan motorik kasar anak didik penderita flat foot.

Pelaksanaan aktivitas ini dilakukan melalui beberapa tahapan aktivitas yaitu:

a. Survey Awal

Survey awal ini dilakukan pada tanggal 14 Oktober 2020, menggunakan metode observasi terhadap salah satu pengajar pada Sekolah Dasar Negeri 1 Tohudan, Colomadu. Dengan tujuan untuk menerima fakta terkait jadwal sosialisasi menggunakan anak didik dam orang tua wali anak didik. Dari output diskusi diperoleh konklusi bahwa pada aplikasi penyuluhan nanti akan terbagi sebagai tiga kali pertemuan. Mengingat masih pada trend pandemik jadi wajib permanen menerapkan protokol kesehatan antara lain physical distancing menggunakan menghadirkan jumlah peserta secara bergantian tidak pada satu saat, memakai masker dan lain-lain.

b. Pelaksanaan kegiatan

Kegiatan ini dilakukan selama tiga hari, pada tanggal 17, 21 dan 24 Oktober 2020. Pelaksanaan aktivitas darma warga ini diwujudkan pada aktivitas penyuluhan kesehatan menggunakan metode ceramah mengenai penggunaan medial arch support terhadap kemampuan motorik kasar anak didik penderita flat foot. 
Penyuluhan kesehatan ini juga dilanjutkan menggunakan hubungan tanya jawab.

a. Evaluasi kegiatan

Evaluasi dilakukan selama proses aktivitas penyuluhan mengenai penggunaan medial arch support terhadap kemampuan motorik kasar anak didik penderita flat foot. Dari hasil evaluasi diperoleh hampir $60 \%$ anak didik dan orang tua wali anak didik telah memakai medial arch support buat kegiatan sehari-hari dan orang tua wali berupaya buat mengontrol agar tidak terjadi kecacatan lebih lanjut menggunakan cara melakukan foot print test dan mengingatkan secara rutin.

\section{PEMBAHASAN}

Materi penyuluhan yang berkenaan menggunakan efek penggunaan medial arch support pada menaikkan kemampuan motorik kasar anak didik penderita flat foot secara singkat disampaikan mulai menurut fungsi foot, anatomi dasar foot, pengertian flat foot, deteksi dini flat foot, pengertian kemampuan motorik kasar, interaksi flat foot menggunakan kemampuan motorik kasar anak, penanganan flat foot, fungsi medial arch support, mengapa medial arch support bisa menaikkan kemampuan motorik kasar. Kegiatan penyuluhan juga didasarkan atas output penelitian yang sudah dilakukan sebelumnya menggunakan topik yang sama sebagai akibatnya memperkuat pernyataan dalam ketika penyuluhan. Diakhir penyuluhan disampaikan cara-cara yang wajib dilakukan orang tua anak buat melakukan pencegahan terjadinya flat foot dan apa yang wajib dilakukan bila flat foot tadi mengganggu kemampuan motorik kasar anak didik.

Setelah aktivitas pengabdian masyarakat berjalan, pemahaman anak didik, orang tua, dan pengajar yang sebagai target pada aktivitas ini sebagai lebih baik, mereka lebih tahu dasar mengenai flat foot, yang berdampak terjadinya penurunan kemampuan motorik kasar dan semakin menyadari pentingnya melakukan penanganannya menggunakan memakai medial arch support.

Evaluasi aktivitas dilakukan selama proses dan akhir aktivitas, dalam aspek pencapaian tujuan dan juga penyelenggaraan penyuluhan. Evaluasi proses dan output dilakukan menggunakan tanya jawab dan observasi. Evaluasi ketika aplikasi penilaian yang dilakukan mencakup keterlibatan dan kemampuan peserta setiap termin. Pada termin akhir, peserta bisa melakukan aktivitas tanya jawab yang berkaitan menggunakan penggunaan medial arch support pada menaikkan kemampuan motorik kasar anak penderita flat foot yang menyebabkan terjadinya amputasi yang lalu pada sesuaikan menggunakan syarat mereka ketika ini.

Indikator keberhasilan selama proses penyuluhan dengan melihat:

a. Kemampuan anak, orang tua, dan pengajar pada pemahaman aktivitas teknis penggunaan medial arch support pada menaikkan kemampuan motorik kasar anak didik penderita flat foot.

b. Keterampilan anak, orang tua dan pengajar pada pemahaman aktivitas teknis pencegahan terjadinya penurunan kemampuan motorik kasar dalam anak yang dikarenakan flat foot.

Indikator keberhasilan pelatihan ini:

a. Menurut $80 \%$ peserta tahu aktivitas aplikasi penyuluhan deteksi dini flat foot. 
b. Menurut $70 \%$ peserta bisa tahu efek penggunaan medial arch support pada menaikkan kemampuan motorik kasar dalam anak flat foot.

Keberhasilan aktivitas darma warga ini dinilai menurut tingkat penyelesaian materi penyuluhan dan pelaksana darma melakukan penilaian menggunakan mengamati respon orang tua anak didik dan pengajar ketika penyuluhan. Pada aktivitas pengabmas ini memakai indera bantu penyuluhan pada warga dan menggunakan bahan model medial arch support dan hand out materi efek penggunaan medial arch support terhadap peningkatan motorik kasar anak penderita flat foot.

\section{KESIMPULAN DAN SARAN}

\subsection{Kesimpulan}

Pelaksanaan aktivitas PKM yg terdiri menurut penyuluhan kesehatan menggunakan metode ceramah, diskusi bisa menaikkan pengetahuan, pemahaman, pencerahan dan mengoptimalkan penggunaan medial arch support terhadap kemampuan motorik kasar anak didik penderita flat foot dalam anak didik Sekolah Dasar Negeri 1 Tohudan, dimana peserta yang hadir sangat aktif dan antusias terhadap aktivitas yangg telah dilakukan.

\subsection{Saran}

Program pengabdian ini Program darma ini diperlukan bisa dilaksanakan secara lebih intensif buat lebih poly menaruh fakta tentang flat foot dan perlu adanya tindak lanjut menurut orang tua dan pengajar tentang penggunaan medial arch support pada menaikkan kemampuan motorik kasar anak.

\section{UCAPAN TERIMA KASIH}

Penghargaan setinggi-tingginya buat Poltekkes Surakarta dan Sekolah Dasar Negeri 1 Tohudan, Colomadu yang sudah mensupport penuh aktivitas ini sebagai akibatnya aktivitas darma warga ini sehingga mampu terealisasi dengan baik.

\section{DAFTAR RUJUKAN}

Bambang Sujiono. (2007). Metode Pengembangan Fisik (Edisi Revisi). Jakarta: Universitas Terbuka.

Daniel et al. (2015). "Static Balance Of Elderly Women Submitted To A Physical Activity Program.http://dx.doi.org/10.1590/1809-9823.2015.14181

Endang Rini Sukamti, MS. (2007). Diklat Perkembangan Motorik. Yogyakarta: Univrsitas Negeri Yogyakarta.

Erol, K. (2015). An Important Cause of Pes Planus: The Posterior Tibial Tendon Dysfunction. Turki: Department of Physical Medicine and Rehabilitation, State Hospital, Nevsehir.

Harris, Edwin J., et al. (2004). Diagnosis and Treatment of Pediatric Flat foot. The 
Journal of Foot \& Ankle Surgery, Volume 43, No.6, November-Desember. American College of Foot and Ankle Surgeons.

Idris, Ferial Hadipoetro. (2010). Filogeni dan Ontogeni Lengkung Kaki Manusia, Majalah Kedokteran Indonesia, Vol: 60, Nomor: 2, Februari 2010. Jakarta: Departemen Kedokteran Fisik dan Rehabilitasi Medik, Fakultas Kedokteran Universitas Indonesia/Rumah Sakit Dr. Cipto Mangunkusumo.

Pearce, Evelyn C. (2006). Anatomi dan Fisiologis Untuk Para Medis, Cetakan kedua puluh Sembilan. Jakarta: PT. Gramedia Pustaka Utama, p. 141-142.

Utomo, Prasetyo. (2018). Pengaruh Penggunaan Medial Arch Support Terhadap Penurunan Derajat Flat Foot Pada Anak Usia 8-12 Tahun. Jurnal Keterampilan Fisik, Volume 3, No.2, November 2018, hlm 58-62. Politeknik Kesehatan Surakarta.

Wibowo, Daniel S. (2008). Anatomi Tubuh Manusia, Jakarta : Grasindo

Yhana Pratiwi dan M. Kristanto. (2015). Upaya Meningkatkan Kemampuan Motorik Kasar (Keseimbangan Tubuh) Anak Melalui Permainan Tradisional Engklek di Kelompok B Tunas Rimba II Tahun Ajaran 2014/2015. 